\title{
AMCoR
}

Asahikawa Medical College Repository http://amcor. asahikawa-med. ac. jp/

NATURE MEDICINE (2005) 11(9):992-997.

Induction of interleukin-8 preserves the angiogenic response in $\mathrm{HIF}-1$ alpha-deficient colon cancer cells

Mizukami, Y; Jo, WS; Duerr, EM; Gala, M; Li, JN; Zhang, XB; Zimmer, MA; Iliopoulos, O; Zukerberg, LR; Kohgo, Y; Lynch, MP; Rueda, BR; Chung, DC 


\section{Induction of interleukin-8 preserves the angiogenic response in HIF-1 deficient colon cancer cells}

Yusuke Mizukami ${ }^{1}$, Won-Seok Jo ${ }^{1}$, Eva-Maria Duerr ${ }^{1}$, Manish Gala ${ }^{1}$, Jingnan $\mathrm{Li}^{1}$, Xiaobo Zhang ${ }^{1}$, Michael A. Zimmer ${ }^{2}$, Othon Iliopoulos ${ }^{2}$, Lawrence R. Zukerberg ${ }^{3}$, Yutaka Kohgo ${ }^{5}$, Maureen P. Lynch ${ }^{4}$, Bo R. Rueda ${ }^{4}$, Daniel C. Chung ${ }^{1}$

${ }^{1}$ Gastrointestinal Unit and ${ }^{2}$ Oncology Unit, Department of Medicine,

${ }^{3}$ Department of Pathology,

${ }^{4}$ Vincent Center for Reproductive Biology, Department of Obstetrics and Gynecology, Massachusetts General Hospital and Harvard Medical School, 50 Blossom Street Boston, MA, 02114 USA

${ }^{5}$ Third Department of Internal Medicine, Asahikawa Medical College, Asahikawa, Japan

Address correspondence to: Daniel C. Chung, E-mail: chung.daniel@mgh.harvard.edu 
Hypoxia inducible factor-1 (HIF-1) is considered a critical mediator of the cellular response to hypoxia through its regulation of genes that control angiogenesis ${ }^{1-4}$. It represents an attractive therapeutic target ${ }^{5,6}$ in colon cancer, one of the few tumor types that exhibits a clinical response to anti-angiogenic therapy ${ }^{7}$. However, it is unclear whether inhibition of HIF-1 alone is sufficient to block tumor angiogenesis ${ }^{8,9}$. In HIF-1 $\alpha$ knock-down DLD-1 colon cancer cells (DLD-1 ${ }^{\text {HIF-kd }}$, the hypoxic induction of vascular endothelial growth factor (VEGF) was only partially blocked. Xenografts remained highly vascularized with microvessel densities identical to DLD-1 $1^{\text {HIF-wt }}$ tumors. In addition to the preserved expression of VEGF, the pro-angiogenic cytokine interleukin-8 (IL-8) was induced by hypoxia in DLD-1 ${ }^{\mathrm{HIF}-\mathrm{kd}}$ but not DLD-1 ${ }^{\mathrm{HIF}-\mathrm{wt}}$ cells. This induction was mediated by the production of hydrogen peroxide and subsequent activation of NF- $\kappa \mathrm{B}$. Furthermore, the KRAS oncogene, which is commonly mutated in colon cancer, enhanced the hypoxic induction of IL-8. A neutralizing antibody to IL-8 dramatically inhibited angiogenesis and tumor growth in DLD-1 ${ }^{\text {HIF-kd }}$ but not DLD- ${ }^{\text {HIF-wt }}$ xenografts, verifying the functional significance of this IL-8 response. Thus, compensatory pathways can be activated to preserve the tumor angiogenic response, and strategies that inhibit HIF-1 $\alpha$ may be most effective when IL-8 is simultaneously targeted.

DLD-1 cells, either with or without HIF-1 $\alpha$ stably knocked-down by siRNA ${ }^{10}$ (DLD-1 ${ }^{\text {HIF- }}$ ${ }^{\mathrm{kd}}$ or DLD-1 ${ }^{\mathrm{HIF}-\mathrm{wt}}$, respectively), were injected subcutaneously into CD1 nude mice. Four weeks after inoculation, both tumor volumes and weights were significantly lower in DLD-1 ${ }^{\mathrm{HIF}-\mathrm{kd}}$ tumors (Figs. 1a,b), indicating an important role for HIF-1 in tumor growth in vivo. We confirmed this finding in an independent colon cancer cell line, Caco2 (Supplementary Fig. 1). 
Large necrotic areas were much more prevalent in DLD-1 ${ }^{\mathrm{HIF}-\mathrm{wt}}$ xenografts (Fig. 1C). Furthermore, a prominent inflammatory infiltrate composed predominantly of neutrophils was observed only in DLD-1 ${ }^{\text {HIF-kd }}$ xenografts (Fig. 1C). Although there were larger areas of necrosis in DLD-1 ${ }^{\text {HIF-wt }}$ xenografts, the cross-sectional surface area of non-necrotic viable tumor was still significantly greater when compared to DLD- ${ }^{\mathrm{HIF}-\mathrm{kd}}$ xenografts $\left(0.33 \mathrm{~cm}^{2}\right.$ vs. $0.16 \mathrm{~cm}^{2}$, respectively, $P=0.025)$. Thus, the difference in size of the tumors cannot be entirely attributed to the larger area of necrosis in the DLD-1 ${ }^{\text {HIF-wt }}$ tumors. A persistent silencing effect of the siRNA/HIF-1 $\alpha$ construct was confirmed in vivo (Fig. 1d).

There was a significant decrease in the Ki-67 labeling index in DLD- ${ }^{\text {HIF-kd }}$ xenografts $\left(41.3 \pm 3.2 \%\right.$ in DLD-1 ${ }^{\mathrm{HIF-wt}}$ tumors vs. $27.4 \pm 2.6 \%$ in DLD- $1^{\mathrm{HIF}-\mathrm{kd}}$ tumors; $\left.\mathrm{P}<0.01\right)$, suggesting that HIF-1 $\alpha$ regulates cellular proliferation in vivo. The apoptotic index was calculated by counting TUNEL positive cells in non-necrotic areas. A small but statistically significant difference in the apoptotic index was observed between the two groups $(3.2 \pm 0.53 \%$ in DLD$1^{\text {HIF-wt }}$ tumors vs. $1.9 \pm 0.42 \%$ in DLD- $1^{\text {HIF-kd }}$ tumors; $\left.P<0.05\right)$, but this difference is unlikely to counterbalance the dramatic difference in proliferation rates.

When DLD- ${ }^{\text {HIF-kd }}$ cells were incubated in hypoxic conditions $\left(1 \% \mathrm{O}_{2}\right)$ in vitro, there was only a $25 \%$ reduction $(P=0.11)$ in the induced levels of VEGF mRNA and protein $(F i g .1 e)$. In the DLD-1 ${ }^{\text {HIF-kd }}$ xenografts, VEGF mRNA and protein levels were also induced (Fig. 1f), though not to the same extent observed in vitro. Compared to the DLD-1 ${ }^{\text {HIF-wt }}$ xenografts, VE GF mRNA levels were $51 \%$ lower $(P=0.028)$ and protein levels were $52 \%$ lower $(P=0.0024)$ in DLD-1 ${ }^{\text {HIF-kd }}$ xenografts. This persistent expression of VEGF was not mediated by HIF- $2 \alpha$, as HIF-2 $\alpha$ mRNA 
and protein levels were barely detectable in normoxic conditions and the gene was not induced by hypoxia (Supplementary Fig. 2).

To specifically address whether hypoxia regulates VEGF in the absence of HIF-1 in vivo, hypoxic areas within the tumor mass were identified utilizing Hypoxyprobe-1 (pimonidazole hydroxychloride). There were large hypoxic regions surrounding the necrotic areas in the center of the DLD-1 ${ }^{\text {HIF-wt }}$ tumors (F ig. 1g). In contrast, DLD-1 ${ }^{\text {HIF-kd }}$ tumors revealed only restricted regions of intratumoral hypoxia. Double immunofluorescence demonstrated that VEGF was preferentially expressed in the hypoxic areas of both DLD-1 ${ }^{\text {HIF-kd }}$ and DLD-1 ${ }^{\text {HIF-wt }}$ xenografts (Fig. 1g).

It is possible that the difference in growth between the xenografts was due to impaired angiogenesis, potentially attributable to lower levels of VEGF in DLD-1 ${ }^{\text {HIF-kd }}$ tumors. However, immunostaining for the endothelial cell marker CD31 revealed abundant microvascular networks in all tumors (Fig. 1h). No quantitative difference in microvessel density was observed (26.1 $\pm 6.3 /$ field in DLD- ${ }^{\text {HIF-wt }}$ and 28.7 \pm 8 .6/field in DLD- $1^{\text {HIF-kd }}$ xenografts), suggesting that high levels of HIF-1 may not be required to stimulate angiogenesis or maintain vessel integrity in DLD-1 tumors.

Although up-regulation of VEGF was preserved in DLD-1 ${ }^{\text {HIF-kd }}$ xenografts, the absolute levels of VEGF were reduced. We therefore determined whether other angiogenic factors may be induced in a compensatory manner to maintain tumor vascularity in the absence of HIF-1. cDNA microarray analysis identified genes that were up-regulated at least 2 -fold by hypoxia but 
whose expression was attenuated less than $30 \%$ when HIF-1 was silenced. VEGF was upregulated 4-fold in DLD-1 ${ }^{\mathrm{HIF}-w \mathrm{t}}$ cells by hypoxia, and this induction was decreased only $10.6 \%$ by HIF-1 silencing (Supplementary Table). In addition, expression of the pro-angiogenic cytokine IL 8 was increased two-fold in DLD-1 ${ }^{\text {HIF-kd }}$ cells cultured in hypoxic conditions compared to DLD-1 ${ }^{\mathrm{HIF}-\mathrm{wt}}$ cells.

Hypoxia up-regulated IL8 mRNA more than 2.5 -fold in DLD- $1^{\text {HIF-kd }}$ cells, but there was no induction in DLD-1 ${ }^{\text {HIF-wt }}$ cells (Fig. 2a). Consistent with this result, the IL-8 level in the supernatant of DLD-1 ${ }^{\text {HIF-kd }}$ cells was increased almost 3 -fold compared to DLD-1 ${ }^{\text {HIF-wt }}$ cells. Similar results were obtained with independent DLD-1 ${ }^{\text {HIF-kd }}$ clones previously established ${ }^{10}$ (data not shown). Extracts from DLD-1 ${ }^{\text {HIF-kd }}$ xenografts also revealed significantly higher IL-8 mRNA and protein levels when compared to DLD-1 ${ }^{\mathrm{HIF}-\mathrm{wt}}$ tumors (Fig. 2b). IL 8 promoter reporter constructs exhibited higher basal activity in DLD-1 ${ }^{\text {HIF-kd }}$ cells (Fig. 2c), and there was further induction of promoter activity in hypoxia that was not observed in the DLD-1 ${ }^{\text {HIF-wt }}$ cells. There was also a 2.1-fold induction of the IL 8 promoter when HIF-1 $\alpha$ was transiently knocked-down in parental DLD-1 cells, indicating this phenomenon was not an artefact of the stable transfection process. In addition, expression of a constitutively active HIF- $1 \alpha / \mathrm{P} 564 \mathrm{~A}$ in DLD- 1 cells failed to induce the IL 8 promoter (1.01 +/- 0.14 fold increase), indicating that HIF-1 does not directly regulate IL 8 gene expression. This hypoxic effect was not unique to DLD-1 cells. Knock-down of HIF- $1 \alpha$ in additional colon cancer cells (ColoHSR, SW 480, and HCT116), pancreatic cancer cells (Panc-1, CAPAN-1), breast cancer cells (MDA-MB-453), and lung cancer cells (HOP-92) revealed a similar induction of IL-8 in hypoxia (Supplementary Fig. 3). Finally, specificity of these siRNA constructs was confirmed by expression of HIF-1 $\alpha$ synonymous codon mutants 
(Supplementary Fig. 4). The absence of HIF-1 can therefore stimulate IL-8 on a transcriptional level, and this is further enhanced in hypoxia.

$\mathrm{NF}-\kappa \mathrm{B}$ is a major regulator of IL-8. NF- $\kappa \mathrm{B}$ reporter activity was increased $151 \%$ $(P<0.01)$ in HIF-1 $\alpha$ knock-down cells (Fig. 2d). Western blotting (Fig. 2e) and immunohistochemistry (Fig. 2f) of tissue xenografts revealed that phosphorylation of the p65 subunit was greater in DLD-1 ${ }^{\mathrm{HIF}-\mathrm{kd}}$ xenografts, suggesting that HIF-1 inhibition does up-regulate the NF- $\kappa$ B pathway in vivo. Densitometry of western blots quantified a $2.0 \pm 0.4$ fold increase in the ratio of phospho-p65/p65 $(\mathrm{P}<0.01)$. The hypoxic induction of the IL 8 promoter in DLD- ${ }^{\text {HIF- }}$ ${ }^{\mathrm{kd}}$ cells was significantly down-regulated by BAY 11-7082, a specific NF-кB inhibitor ${ }^{11}$ (Fig. $2 \mathrm{~g}$ ). Thus, activation of the NF- $\mathrm{B}$ pathway is important for the induction of IL-8 in the absence of HIF-1.

We then speculated that HIF-1 inhibition may enhance the production of hydrogen peroxide, a reactive oxygen species (ROS) that can activate $N F-\kappa B^{12,13}$. Hypoxic conditions can lead to the increased production of $\operatorname{ROS}^{14,15}$, and scavenging of ROS is often achieved by increased production of pyruvate ${ }^{16}$ that occurs when cells shift from oxidative to glycolytic metabolism. This shift depends upon HIF-1 $\alpha^{17}$. DLD-1 $1^{\text {HIF-kd }}$ cells released more hydrogen peroxide in vitro, and hypoxia further enhanced its production (Fig. 3a). Four distinct chemical inhibitors of ROS production (N-acetyl-L-cysteine (NAC), pyrrolidinedithiocarbamate (PDTC), rotenone (Rot), and diphenylene iodonium (DPI)) each strongly blocked the induction of NF-kB promoter activity by hypoxia in DLD-1 $1^{\mathrm{HIF}-\mathrm{kd}}$ cells (Fig. 3b). Finally, exogenous administration of the long-acting $\mathrm{H}_{2} \mathrm{O}_{2}$ analogue, t-butyl hydroperoxide (t-BH), stimulated the production of IL- 
8 in parental DLD-1 cells. This induction was inhibited by BAY 11-7082 (Fig. 3c), again demonstrating that NF- $\mathrm{B}$ mediates this effect of ROS.

In contrast to DLD-1 ${ }^{\text {HIF-kd }}$ cells, hypoxic induction of IL-8 mRNA (Fig. 3d) and protein (data not shown) was not observed in Caco $2^{\text {HIF-kd }}$ colon cancer cells ${ }^{10}$. Since DLD-1 cells harbor a mutant KRAS oncogene $\left(K_{R A S^{D 13}}\right)$ whereas Caco2 cells are wild-type $\left(K R A S^{W T}\right)$, we speculated that oncogenic KRAS may play a role in the hypoxic induction of $\mathrm{IL}-8^{18}$. When oncogenic $\mathrm{KRAS}^{\mathrm{V} 12}$ was expressed in Caco2 ${ }^{\mathrm{HIF-kd}}$ cells, hypoxia up-regulated IL 8 mRNA 2.5-fold, whereas the effect was not observed in $\mathrm{Caco} 2^{\mathrm{HIF}-\mathrm{wt}}$ cells or in $\mathrm{Caco} 2^{\mathrm{HIF}-\mathrm{kd}}$ cells exposed to hypoxia only (Fig. 3d). KRAS ${ }^{\mathrm{V} 12}$ only modestly induced IL 8 mRNA in Caco ${ }^{\text {HIF-kd }}$ cells in normoxic conditions. Expression of $\mathrm{KRAS}^{\mathrm{V} 12}$ in $\mathrm{Caco} 2^{\mathrm{HIF}-\mathrm{wt}}$ cells also up-regulated the IL 8 promoter, but this activation was more pronounced in $\mathrm{Caco} 2^{\mathrm{HIF}-\mathrm{kd}}$ cells in hypoxia (Fig. 3e). BAY 11-7082 blocked the induction of the IL 8 promoter by hypoxia and KRAS ${ }^{\mathrm{V} 12}$ (Fig. 3e).

Exogenous expression of oncogenic KRAS may act supra-physiologically. Endogenous $K_{R A S^{D 13}}$ in DLD-1 cells was therefore silenced by siRNA and this resulted in a $50 \%$ reduction of KRAS protein levels, consistent with a silencing effect of the one mutant allele ${ }^{19}$. Knock-down of KRAS ${ }^{\mathrm{D} 13}$ attenuated the hypoxic induction of NF- $\mathrm{KB}$ and IL-8 promoter activity (Fig. 3f) as well as IL 8 mRNA levels (Fig. 3g) in DLD-1 ${ }^{\text {HIF-kd }}$ but not in DLD-1 ${ }^{\text {HIF-wt }}$ cells. These observations were confirmed in the Panc-1 pancreatic and PC3 prostate cancer cell lines, indicating the broader importance of KRAS on this alternative regulation of IL-8 (Supplementary Fig. 5). Furthermore, the stimulatory effect of oncogenic KRAS on NF-кB was observed in hypoxic conditions or in the presence of reactive oxygen species ( $F$ igs. $3 d, h$ ). 
Collectively, these studies indicate that IL- 8 can be induced in hypoxia through the activation of $\mathrm{NF}-\kappa \mathrm{B}$ in the absence of HIF-1, and that oncogenic KRAS can further stimulate NF- $\mathrm{BB}$ in hypoxic conditions to up-regulate this alternative angiogenic pathway.

Finally, we sought to determine the functional significance of IL-8 production in HIF-1 deficient tumors. The observation that DLD-1 ${ }^{\text {HIF-kd }}$ xenografts displayed a marked inflammatory infiltrate (Fig. 1C) was consistent with a functional role for IL-8, a potent neutrophil chemokine ${ }^{18}$. Intraperitoneal administration of the IL-8 neutralizing antibody MAB208 resulted in complete regression of $25 \%$ of DLD- ${ }^{\text {HIF-kd }}$ xenografts, and among the other detectable DLD- ${ }^{\text {HIF-kd }}$ tumors, there was a $61.3 \%$ reduction in tumor volume $(P<0.01)$ and $61.8 \%$ reduction in tumor weight $(P<0.01)$ compared to tumors treated with control IgG ( $F$ igs. $4 a, b)$. In contrast, there was only a $24.8 \%(\mathrm{P}=0.28)$ and $15.6 \%(\mathrm{P}=0.35)$ reduction in tumor volume and weight, respectively, in DLD-1 ${ }^{\text {HIF-wt }}$ xenografts. Although treatment with MAB208 resulted in a decrease in the Ki-67 labeling index and increase in apoptosis in the DLD- ${ }^{\text {HIF-kd }}$ xenografts (Fig. 4C), in vitro studies revealed that MAB208 did not directly inhibit tumor cell growth (Fig. 4d). Rather, treatment with MAB208 resulted in a dramatic inhibition of angiogenesis. The microvessel density in DLD- $1^{\text {HIF-kd }}$ xenografts was reduced $46.5 \%(P<0.001)$ compared to a $14.5 \%$ reduction $(P=0.11)$ in DLD-1 ${ }^{\text {HIF-wt }}$ xenografts (Fig. 4e, upper panels). Confocal microscopy of tumor sections after lectin perfusion verified that vascular integrity was compromised in DLD-1 ${ }^{\text {HIF-kd }}$ xenografts treated with MAB208 (Fig. 4e, lower panels). In addition to reduced vessel number, the vessels were markedly narrowed and fragmented. Specifically, the mean vessel diameter fell from 22.4 $\mu \mathrm{m}$ to $5.9 \mu \mathrm{m}(\mathrm{P}=0.0002)$ when DLD- $1^{\mathrm{HIF}-\mathrm{kd}}$ xenografts were treated with MAB208, but there was no change in the DLD-1 ${ }^{\text {HIF-wt }}$ xenografts $(26.5 \mu \mathrm{m}$ vs. $24.8 \mu \mathrm{m}$ with MAB208, P $=$ NS). 
Neutralization of both IL-8 and VEGF in DLD-1 ${ }^{\mathrm{HIF}-\mathrm{kd}}$ xenografts had an additive effect on the inhibition of tumor growth (Fig. 4f), demonstrating that each factor can regulate tumorigenesis independently.

In summary, we have demonstrated that HIF-1 $\alpha$ deficiency in colon cancer cells can inhibit proliferation and overall growth but not angiogenesis. There are conflicting reports of the role of HIF-1 in tumor cell proliferation. $\mathrm{Hifl}^{-1-}$ ES-derived teratocarcinomas exhibit both reduced as well as increased growth ${ }^{2,20}$. Among human tumors, overexpression of HIF-1 $\alpha$ has been associated with improved survival in patients with head and neck cancers ${ }^{21}$ and HIF-1 can inhibit the growth of renal carcinoma cells ${ }^{22}$. This may be mediated through the induction of the cell cycle inhibitors $\mathrm{p} 21$ and $\mathrm{p} 27^{23}$. It has been speculated that HIF-1 may have intrinsic functions to either promote or inhibit tumor growth that depends upon the cellular context ${ }^{24}$. The preservation of angiogenesis in our model can be explained by persistent expression of VEGF as well as induction of the pro-angiogenic factor, IL-8. IL-8 was stimulated by ROSmediated activation of NF- $\mathrm{BB}$, and this was enhanced by oncogenic KRAS. Neutralization of IL8 in HIF-1 deficient tumors led to a dramatic inhibition of angiogenesis and tumor growth.

Studies of lung cancer cells harboring a KRAS mutation have also demonstrated a pivotal role for IL-8 in tumor angiogenesis ${ }^{25}$. Collectively, these findings highlight the complex role of HIF-1 $\alpha$ in colorectal tumorigenesis, the diversity of pathways utilized by tumors to stimulate angiogenesis, and the potential for combination anti-angiogenic regimens that target both HIF-1 and IL-8. 


\section{M ethods}

Cell lines. DLD-1 and Caco2 cells (ATCC) were stably transfected with HIF-1 $\alpha$ siRNA constructs (pSuper.retro, OligoEngine), pSR.HIF-1 $\alpha 1470$ or pSR.HIF-1 $\alpha 2192^{10}$. Three independent DLD-1 clones stably expressing pSR.HIF-1 $\alpha 1470$ and two independent clones expressing pSR.HIF-1 $\alpha 2192$ exhibited similar responses to hypoxia with respect to induction of NF- $\kappa \mathrm{B}$ and IL-8. In a pilot xenograft study, growth, microvascular density, VEGF and IL-8 levels were similar between a pSR.HIF-1 11470 clone and pSR.HIF-1 $\alpha 2192$ clone. Hypoxic conditions $\left(1 \% \mathrm{O}_{2}\right)$ were achieved with a sealed hypoxia chamber (Billups-Rothenberg) in serum free UltraCulture medium (Cambrex $)^{10}$. Transient transfections were performed using Lipofectamine 2000 (Invitrogen).

Plasmid constructs. The IL- 8 reporter ${ }^{26}, \mathrm{NF}-\kappa \mathrm{B}$ reporter, and phr-GFP-K-ras ${ }^{\mathrm{V} 12}$ plasmids have been described ${ }^{27}$. Site directed mutagenesis was performed to obtain the phr-GFP-Kras ${ }^{\mathrm{D} 13}$ construct. pSuper.K-rasD13 (pSR.K-ras ${ }^{\text {D13 }}$ ) was constructed by subcloning the sequence 5 GGAGCTGGTGACGTAGGCA. For control siRNA, pSR.cont, the sequence 5'GCGCGCTTTGTAGGATTCG was utilized ${ }^{28}$.

Transfections and R eporter Assays. 0.1-0.2 $\mu \mathrm{g}$ reporter constructs were co-transfected with 2 ng of pRL-CMV (Promega) and luciferase activity was measured with the Dual Luciferase Reporter Assay System (Promega). pRL-null, a promoter-less Renilla construct, was used when cells were co-transfected with a K-ras expression vector ${ }^{29}$. The relative luciferase activity was 
calculated as Firefly /Renilla luciferase activity. The level of 'hypoxic induction' was the ratio between the relative luciferase activity in hypoxia to that in normoxia.

Xenograft tumor model. $2 \times 10^{6}$ cells were injected subcutaneously into the flanks of 6-8-week CD1 female nude mice (6 mice/arm). Tumors were measured with calipers and volume was calculated as [length $\mathrm{x}$ width $\left.{ }^{2}\right]$ x 0.5. Neutralizing antibody to IL-8 (MAB208, clone 6217.111; R\&D Systems) and/or VEGF (MAB293, R\&D Systems) was administered i.p when tumors reached $5 \mathrm{~mm} .100 \mu \mathrm{g}$ of MAB208 and/or $25 \mu \mathrm{g}$ of MAB293 was injected on days 7, 9, 11, 14, $16,18,21$, and 23 , before mice were sacrificed at day 25 . To assess hypoxic regions, mice were injected with $60 \mathrm{mg} / \mathrm{kg}$ pimonidazol hydrochloride (Hypoxyprobe-1, Chemicon) i.p., $1.5 \mathrm{hr}$ before sacrifice. To visualize functional tumor microvessels, $100 \mu \mathrm{g}$ FITC-labeled tomato lectin (Vector Laboratories) was injected i.v., and mice were heart-perfused with $4 \%$ paraformaldehyde. This protocol was approved by the Animal Care and Use Committee of the Massachusetts General Hospital.

Immunohistochemistry. $5 \mu \mathrm{m}$ sections from fresh frozen tumors were treated with acetone and endogenous peroxidase was blocked with $3 \% \mathrm{H}_{2} \mathrm{O}_{2}$. The sections were incubated with a CD31 antibody, MEC13.3 (1:50; Pharmingen) overnight at $4{ }^{\circ} \mathrm{C}$. Blood vessels were counted in 5-10 random viable fields (200x). To detect tumor hypoxia, formalin fixed sections were treated with $0.01 \%$ pronase and incubated with Hypoxpyrobe-1 antibody Mab1 (1:50; Chemicon). For other immunohistochemical studies, xenograft tissues were fixed in $10 \%$ neutral buffered formalin. TUNEL staining was performed with the ApoAlert DNA fragmentation detection kit (Clontech). 
Ki-67 staining was performed with the MIB-1 antibody (1:100; DAKO) and staining for phospho-p65 (Ser 563) (1:50; Cell Signaling) was also performed.

Real-time PCR assay. RNA was extracted using the RNeasy kit (Qiagen) and quantitative reverse-transcription PCR was performed using the SuperScript III platinum Two-Step qRT-PCR Kit (Invitrogen). Primer sequences for VEGF, IL-8, and 18S RNA are available upon request. A fluorogenic SYBR Green and MJ research detection system were used for real time quantification.

I mmunoblotting. Immunoblot analysis for HIF-1 $\alpha$ (clone 54, 1:250; Transduction Laboratories), HIF-2 $\alpha$ (1:250, Novus), Glut-1 (GT-11A, 1:1000; Alpha Diagnostic International), VEGF (Ab-2, 1:40; Calbiochem), phospho (Ser 563)- and total-NF-кB p65 (1:1000; both Cell Signaling), Kras (F234, 1 :200; Santa Cruz) and $\beta$-actin (AC15, $1 \mu \mathrm{g} / \mathrm{mL}$; Sigma) were performed after SDSPAGE and electrophoretic transfer to PVDF membranes ${ }^{10}$.

ELISA. VEGF and IL-8 protein levels of conditioned medium and tissue lysates were assayed utilizing specific ELISA kits (Quantikine, R\&D Systems).

M icroarray analysis. Sample preparation and processing procedures were performed as described in the Affymetrix GeneChip Expression Analysis Manual (Santa Clara). The labeled cRNA samples were hybridized to the complete Affymetrix human U133 GeneChip set (HGU133A). 
$\mathrm{H}$ ydrogen peroxide studies. Measurement of $\mathrm{H}_{2} \mathrm{O}_{2}$ was performed using the Amplex Red Hydrogen peroxide Assay Kit and the CM-H2DCFDA reagent (both Molecular Probe). Cells were exposed to hypoxia for $10 \mathrm{~h}$, and then culture medium was switched to Krebs-Ringer phosphate buffer ${ }^{30}$ containing $100 \mu \mathrm{M}$ Amplex Red reagent and 0.2 U/mL HRP. After additional incubation in hypoxia for 1h, fluorescence was measured in 96-well plates by Spectra MAX GEMINI XS microplate fluorometer (Molecure Devices). Cells were also incubated with $10 \mu \mathrm{M}$ CM-H2DCFDA for 30 minutes in RPMI without phenol red. Fluorescence was measured in 96 well plates and values were normalized to cell number. 20 or $40 \mu \mathrm{M}$ t-butyl hydroperoxide (t-BH, Sigma) was added to the culture media of DLD- 1 cells every 30 minutes for 6 hours, and IL-8 mRNA levels were measured by qRT-PCR.

Statistical analysis. Statistical analyses were performed with a two-tailed, unpaired Student's ttest. 


\section{Acknowledgements}

We thank the following individuals for generously sharing these plasmids: C. Reinecker

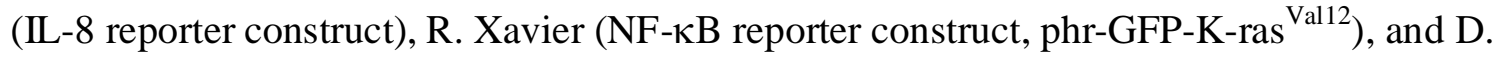
Tenen (pRL-null). We also thank Y. Kamegaya, M. Takeda, M. Ii, E. di Tomaso, T. Padera, P. $\mathrm{Au}$, and R. Tyszkowski for assistance with tissue analysis. DNA microarray studies were performed at the DNA Microarray Core Facility at the Massachusetts General Hospital Cancer Center. Confocal microscopy was performed through the Imaging Core of the Center for Study of Inflammatory Bowel Diseases. This work was supported by research grant NIH CA92594 to D.C.C. O.I. was supported by NIH CA104574, B.R.R. was supported by NIH CA098333, M.A.Z. was supported by VHL Family Alliance, M.G. was supported by an ADHF student fellowship award, and E-M.D. was supported by a postdoctoral fellowship award from the Deutsche Forschungsgemeinschaft. 


\section{Figure legends}

\section{Figure 1}

Growth of DLD-1 ${ }^{\text {HIF-kd }}$ cells in vivo. (a) Tumor volume and weight of DLD-1 ${ }^{\text {HIF-wt }}$ and DLD$1^{\text {HIF-kd }}$ xenografts. * indicates $P<0.05$. (b) Gross appearance of xenografts and excised tumors at 4 weeks (bar $=5 \mathrm{~mm}$ ) (c) $\mathrm{H} \& \mathrm{E}$ staining of resected tumors (left bars $=1 \mathrm{~mm}$, right bars $=50$ $\mu \mathrm{m})$. (d) Immunoblotting for HIF-1 $\alpha$ and Glut-1 in DLD-1 ${ }^{\mathrm{HIF}-\mathrm{kd}}$ xenografts. VE GF mRNA and protein levels in cultured DLD-1 cells (e) and in tumor xenografts (f) were measured. $(g)$ Intratumoral 'hypoxia' was detected by immunohistochemistry for Hypoxyprobe-1 (bar = $1 \mathrm{~mm}$ ). Immunofluorescent staining for VEGF (Texas red) and Hypoxyprobe-1 (FITC) $(\mathrm{bar}=100 \mu \mathrm{m})$. (h) Immunohistochemistry for CD-31/PECAM and quantification of microvessel density in DLD-1 xenografts $($ bar $=100 \mu \mathrm{m})$.

\section{Figure 2}

Knock-down of HIF-1 facilitates the induction of IL- 8 by NF- $\kappa \mathrm{B}$ during hypoxic conditions. IL8 mRNA and protein levels in (a) cultured DLD-1 cells and (b) DLD-1 xenografts. (c) IL 8 promoter activity during hypoxia in DLD- $1^{\mathrm{HIF}-\mathrm{kd}}$ and DLD-1 ${ }^{\mathrm{HIF}-\mathrm{wt}}$ cells. (d) NF- $\kappa \mathrm{B}$ reporter activity in hypoxic conditions in DLD- $1^{\mathrm{HIF}-\mathrm{kd}}$ cells. In (b,c,d), open bars = normoxic conditions, solid bars $=$ hypoxic conditions. (e) Immunoblotting for NF- $\kappa \mathrm{B}, \mathrm{p} 65$ subunit and phospho-p65

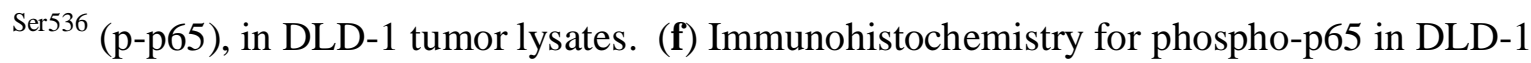
xenografts (shown as Texas Red) (bar $=50 \mu \mathrm{m})$. (g) Effect of NF- $\kappa$ B inhibition on IL-8 promoter activity with BAY 11-7082. 


\section{Figure 3}

Increased production of reactive oxygen species in HIF-kd cells expressing K-ras. (a) Increased production of hydrogen peroxide in DLD-1 ${ }^{\mathrm{HIF}-\mathrm{kd}}$ cells as measured by Amplex Red (left panel) and DCF fluorescence (right panel). (b) Effect of inhibitors of hydrogen peroxide production, NAcetyl-L-cysteine (NAC), pryrolidinedithiocarbamate (PDTC), rotenone (Rot), and diphenylene iodonium (DPI) on induction of NF- $\mathrm{B}$ reporter activity by hypoxia. $* \mathrm{P}<0.01$. (c) Induction of IL 8 gene expression by t-butyl hydroperoxide (t-BH) and inhibition by $5 \mu \mathrm{M}$ BAY 11-7082. (d) Synergistic effect of hypoxia and KRAS ${ }^{\mathrm{V} 12}$ on IL-8 induction in Caco2 ${ }^{\mathrm{HIF}-\mathrm{kd}}$ cells. (e) Induction of IL-8 promoter activity by KRAS ${ }^{\mathrm{V} 12}$ and hypoxia and inhibition by BAY 11-7082.

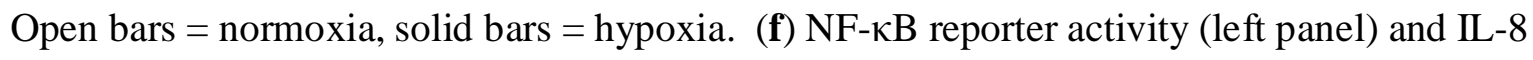
promoter activity (right panel) after silencing of endogenous mutant K RAS by siRNA, pSR/K$\operatorname{ras}^{\text {D13 }}$. (g) IL 8 mRNA levels in DLD- $1^{\text {HIF-kd }}$ cells after silencing of endogenous mutant KRAS by pSR.K-ras ${ }^{\mathrm{D} 13}$. Open bars $=$ normoxia, solid bars = hypoxia. (h) Effect of $\mathrm{KRAS}^{\mathrm{V} 12}$ and $40 \mu \mathrm{M} \mathrm{t}-$ butyl hydroperoxide ( $\mathrm{t}-\mathrm{BH})$ on $\mathrm{NF}-\mathrm{\kappa B}$ reporter activity in Caco2 cells.

\section{Figure 4}

Role of IL-8 in tumor angiogenesis in vivo. Tumor volume (a) and weight (b) of DLD-1 ${ }^{\text {HIF-wt }}$ and DLD- ${ }^{\text {HIF-kd }}$ xenografts after treatement with neutralizing antibody to IL-8, MAB208 (* $\mathrm{P}<0.01, \mathrm{DLD}-1^{\mathrm{HIF}-\mathrm{kd}}+\mathrm{IgG}$ vs. DLD-1 $\left.{ }^{\mathrm{HIF}-\mathrm{kd}}+\mathrm{MAB} 208\right)$. Bars indicate $5 \mathrm{~mm}$. There was no change in the percentage of non-necrotic viable tumor with MAB208 treatment (DLD-1 ${ }^{\text {HIF-wt: }}$ $69.8 \%$ vs. $69.9 \%$; DLD-1 ${ }^{\text {HIF-kd }}: 87.8 \%$ vs. $83.9 \%$, IgG vs. MAB208, P = NS). (c) Ki-67 labeling 
and TUNEL indices in MAB208 treated xenografts. (d) Growth of DLD-1 cells in the presence of MAB208 under hypoxic conditions. (e) Blood vessels visualized by CD31 immunohistochemistry (upper panels, bar $=100 \mu \mathrm{m})$ and lectin perfusion (lower panels, bar $=50$ $\mu \mathrm{m})$. Note the narrow and fragmented vessels in DLD-1 ${ }^{\text {HIF-kd }}+$ MAB208. (f) Growth of DLD$1^{\mathrm{HIF-kd}}$ xenografts when treated with a neutralizing VEGF antibody (MAB293) and/or a neutralizing antibody to IL-8 (MAB208). In these xenografts, the percentage of viable nonnecrotic tumor fell slightly to $74.7 \%$ from $87.8 \%$ in animals who received control antibody only $(P=0.1)$. 


\section{References}

1. Denko, N.C. et al. Investigating hypoxic tumor physiology through gene expression patterns. Oncogene 22, 5907-5914 (2003).

2. Carmeliet, P. et al. Role of HIF-1alpha in hypoxia-mediated apoptosis, cell proliferation and tumour angiogenesis. Nature 394, 485-490 (1998).

3. Pugh, C.W. \& Ratcliffe, P.J. Regulation of angiogenesis by hypoxia: role of the HIF system. Nat. M ed. 9, 677-84 (2003).

4. Tang, N. et al. Loss of HIF-1 alpha in endothelial cells disrupts a hypoxia-driven VEGF autocrine loop necessary for tumorigenesis. Cancer Cell 6, 485-495 (2004).

5. Kung, A.L., Wang, S., Klco, J.M., Kaelin, W.G. \& Livingston, D.M. Suppression of tumor growth through disruption of hypoxia-inducible transcription. Nat. M ed. 6, 13351340 (2000).

6. Semenza, G.L. Targeting HIF-1 for cancer therapy. Nat. Rev. Cancer 3, 721-732 (2003).

7. Hurwitz, H. et al. Bevacizumab plus irinotecan, fluorouracil, and leucovorin for metastatic colorectal cancer. N. Engl. J. M ed 350, 2335-2342 (2004).

8. Maxwell, P.H. et al. Hypoxia-inducible factor-1 modulates gene expression in solid tumors and influences both angiogenesis and tumor growth. Proc. Natl. Acad. Sci. U.S.A. 94, 8104-8109 (1997).

9. Ryan, H.E. et al. Hypoxia-inducible factor-1alpha is a positive factor in solid tumor growth. Cancer Res. 60, 4010-4015 (2000).

10. Mizukami, Y. et al. Hypoxia-inducible factor-1-independent regulation of vascular endothelial growth factor by hypoxia in colon cancer. Cancer Res. 64, 1765-1772 (2004).

11. Pierce, J.W. et al. Novel inhibitors of cytokine-induced IkappaBalpha phosphorylation and endothelial cell adhesion molecule expression show anti-inflammatory effects in vivo. J. Biol. Chem. 272, 21096-21103 (1997).

12. Schreck, R., Rieber, P. \& Baeuerle, P.A. Reactive oxygen intermediates as apparently widely used messengers in the activation of the NF-kappa B transcription factor and HIV-1. EM B 0 J . 10, 2247-2258 (1991).

13. Michiels, C., Minet, E., Mottet, D. \& Raes, M. Regulation of gene expression by oxygen: NF-kappaB and HIF-1, two extremes. F ree Radic. Biol. M ed. 33, 1231-1242 (2002).

14. Chandel, N.S. et al. Mitochondrial reactive oxygen species trigger hypoxia-induced transcription. Proc. Natl. Acad. Sci. U S.A. 95, 11715-11720 (1998).

15. Chandel, N.S. et al. Reactive oxygen species generated at mitochondrial complex III stabilize hypoxia-inducible factor-1 alpha during hypoxia: a mechanism of $\mathrm{O} 2$ sensing. J . Biol. Chem. 275, 25130-25138 (2000).

16. Brand, K.A. \& Hermfisse, U. Aerobic glycolysis by proliferating cells: a protective strategy against reactive oxygen species. FASE B J . 11, 388-395 (1997).

17. Seagroves, T.N. et al. Transcription factor HIF-1 is a necessary mediator of the pasteur effect in mammalian cells. Mol. Cell. Biol. 21, 3436-3444 (2001).

18. Sparmann, A. \& Bar-Sagi, D. Ras-induced interleukin-8 expression plays a critical role in tumor growth and angiogenesis. Cancer Cell 6, 447-458 (2004).

19. Shirasawa, S., Furuse, M., Yokoyama, N. \& Sasazuki, T. Altered growth of human colon cancer cell lines disrupted at activated Ki-ras. Science 260, 85-88 (1993).

20. Ryan, H.E., Lo, J. \& Johnson, R.S. HIF-1 alpha is required for solid tumor formation and embryonic vascularization. EM B O J . 17, 3005-3015 (1998). 
21. Beasley, N.J. et al. Hypoxia-inducible factors HIF-1alpha and HIF-2alpha in head and neck cancer: relationship to tumor biology and treatment outcome in surgically resected patients. Cancer Res. 62, 2493-2497 (2002).

22. Raval, R.R. et al. Contrasting properties of hypoxia-inducible factor 1 (HIF-1) and HIF-2 in von Hippel-Lindau-associated renal cell carcinoma. M ol. C ell. Biol. 25, 5675-5686 (2005).

23. Mack, F.A., Patel, J.H., Biju, M.P., Haase, V.H. \& Simon, M.C. Decreased growth of Vhl-/- fibrosarcomas is associated with elevated levels of cyclin kinase inhibitors $\mathrm{p} 21$ and p27. M ol. Cell. Biol. 25, 4565-4578 (2005).

24. Koshiji, M. \& Huang, L.E. Dynamic balancing of the dual nature of HIF-1alpha for cell survival. Cell Cycle 3, 853-854 (2004).

25. Arenberg, D.A. et al. Inhibition of interleukin-8 reduces tumorigenesis of human nonsmall cell lung cancer in SCID mice. J . Clin. Invest 97, 2792-2802 (1996).

26. Ofori-Darko, E. et al. An OmpA-like protein from Acinetobacter spp. stimulates gastrin and interleukin-8 promoters. Infect. Immun. 68, 3657-3666 (2000).

27. Khokhlatchev, A. et al. Identification of a novel Ras-regulated proapoptotic pathway. Curr. Biol. 12, 253-265 (2002).

28. Zhang, L., Fogg, D.K. \& Waisman, D.M. RNA interference-mediated silencing of the S100A10 gene attenuates plasmin generation and invasiveness of Colo 222 colorectal cancer cells. J . Biol. Chem. 279, 2053-2062 (2004).

29. Behre, G., Smith, L.T. \& Tenen, D.G. Use of a promoterless Renilla luciferase vector as an internal control plasmid for transient co-transfection assays of Ras-mediated transcription activation. Biotechniques 26, 24-28 (1999).

30. Mohanty, J.G., Jaffe, J.S., Schulman, E.S. \& Raible, D.G. A highly sensitive fluorescent micro-assay of $\mathrm{H} 2 \mathrm{O} 2$ release from activated human leukocytes using a dihydroxyphenoxazine derivative. J . Immunol. M ethods 202, 133-141 (1997). 


\begin{tabular}{lcc} 
Fragment name & Gene & $\begin{array}{c}\text { Fold induction } \\
\text { by hypoxia }\end{array}$ \\
\hline 210512_s_at & VEGF-A & 4.0 \\
205463_s_at & PDGFA & 2.2 \\
204200_s_at & PDGFB & 0.7 \\
204421_s_at & basic FGF & 1.1 \\
20442? s at & FGF? & 0.5 \\
205608_s_at & angiopoietin-1 & 0.9 \\
202023 at & Fnhrin A1 & 2.5 \\
205016_at & TGF- $\alpha$ & 1.2 \\
209747 at & TGF-R3 & 1.6 \\
202859 x at & interleıkin-8 & 0.8 \\
210037_s_at & inducible nitric oxide synthase & 2.3 \\
205141_at & angiogenin & 4.0 \\
200785_s_at & Jw density lipoprotein-related protein-1 (LRP1 & 0.6 \\
201809_s_at & endoglin (ENG) & 6.9 \\
202912_at & adrenomedullin (ADM) & 3.5 \\
203666_at & stromal cell-derived factor-1 (SDF-1) & 2.1 \\
207094_at & interleukin 8 receptor, $\alpha$ (IL8RA, CXCR1) * & 0.8 \\
207008_at & interleukin 8 receptor, $\beta$ (IL8RB, CXCR2) * & 2.8 \\
\hline
\end{tabular}

*expression level in normoxia categorized as "absent" 
'hange in hypoxic induction

by HIF knock-down (\%)

$-10.6$

103.3

35.1

$-84.6$

$-86.6$

$-26.6$

$-15.7$

$-44.9$

$-19.3$

$81 ?$

$-7.8$

14.4

$-14.4$

$-65.7$

$-24.4$

$-38.8$

$-19.2$

$-74.0$ 


\section{Figure 1}

a

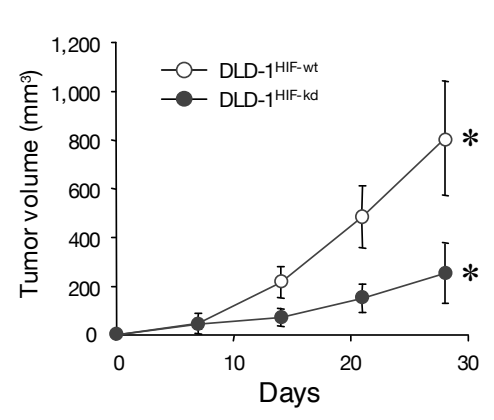

C DLD-1HIF-wt

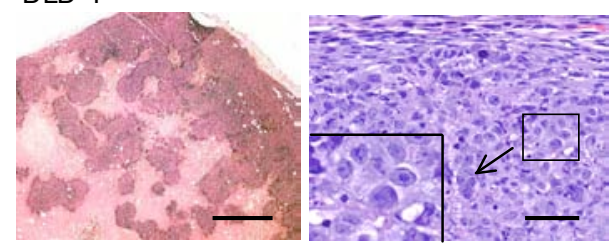

DLD-1 1 HF-kd

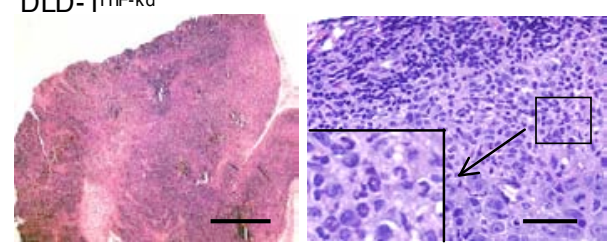

e

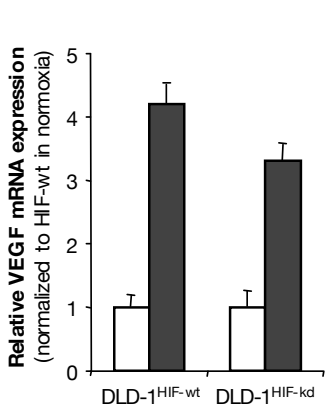

g

DLD-1HF-wt
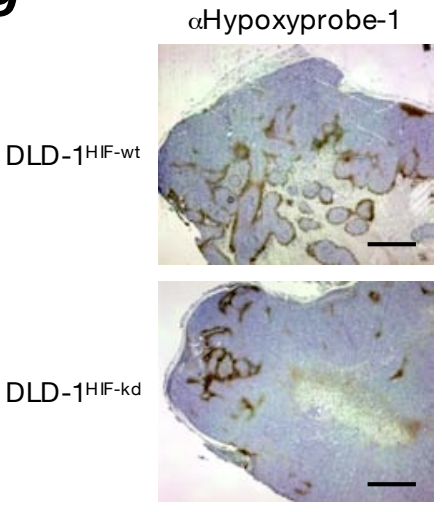

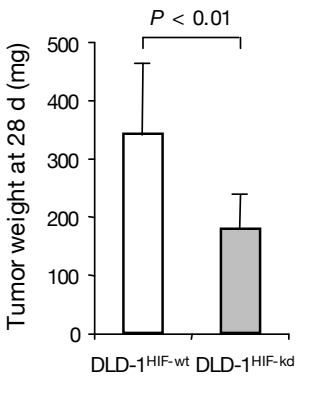

d

HIF-1 $1 \alpha$

b
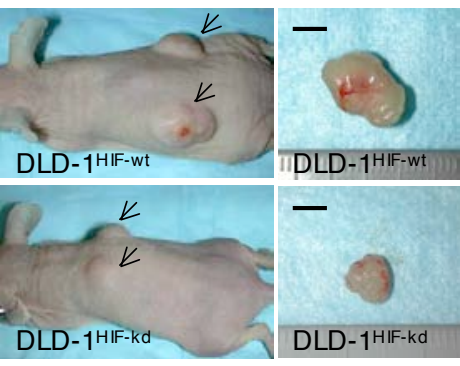

Glut-1

$\beta$-actin $---\infty-\infty-\infty$

f

in vivo
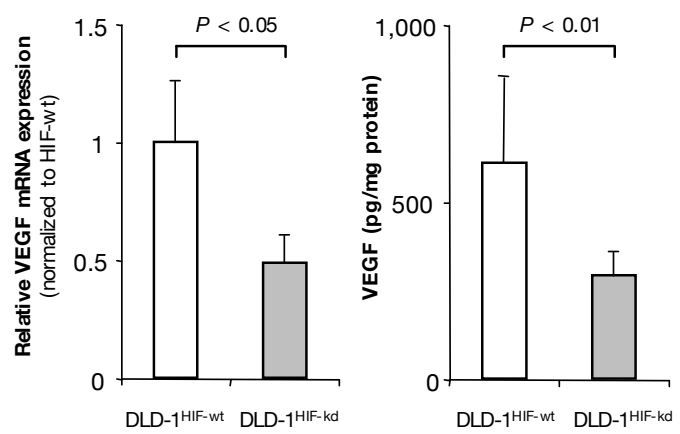

$\boldsymbol{h}$
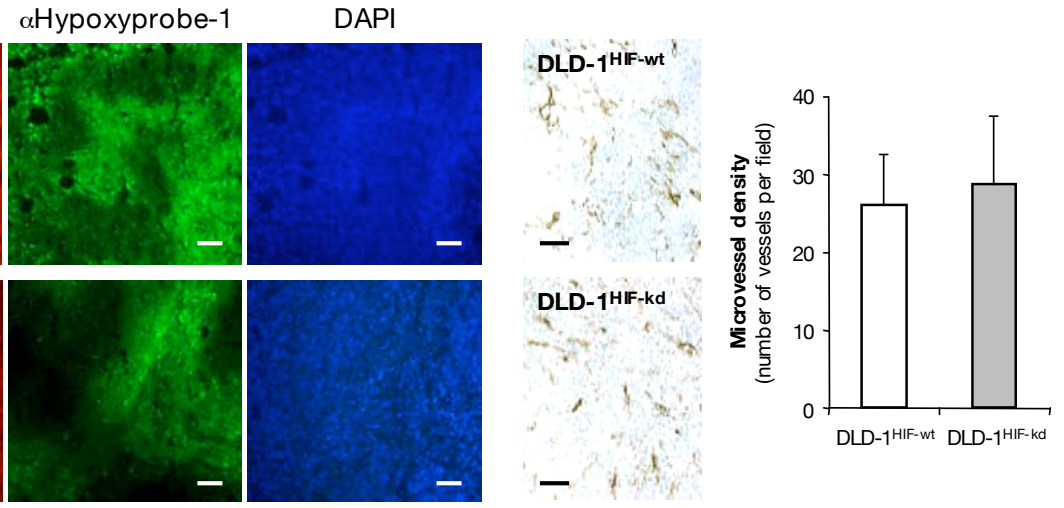
Figure 2

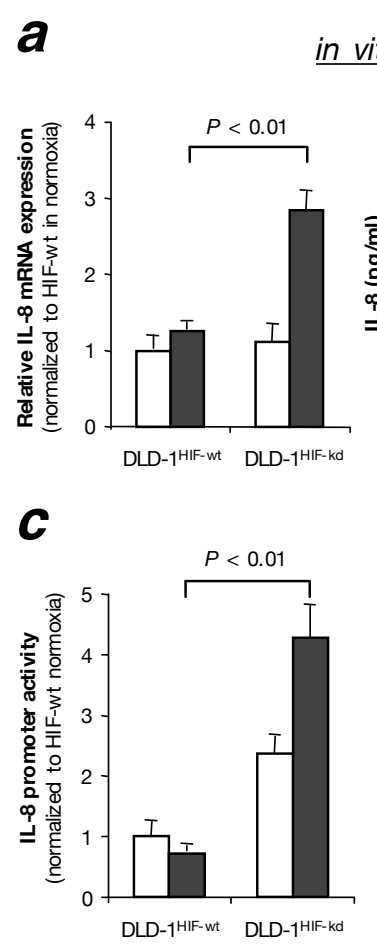

$\boldsymbol{b}$ in vivo
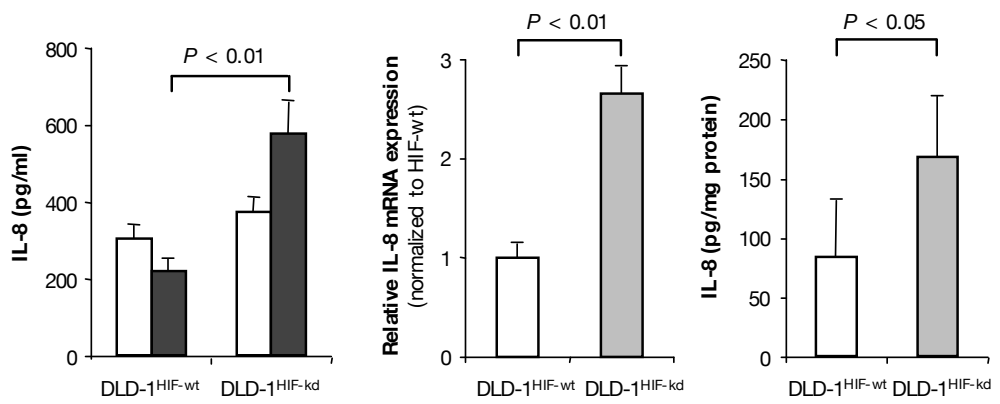

$d$

e
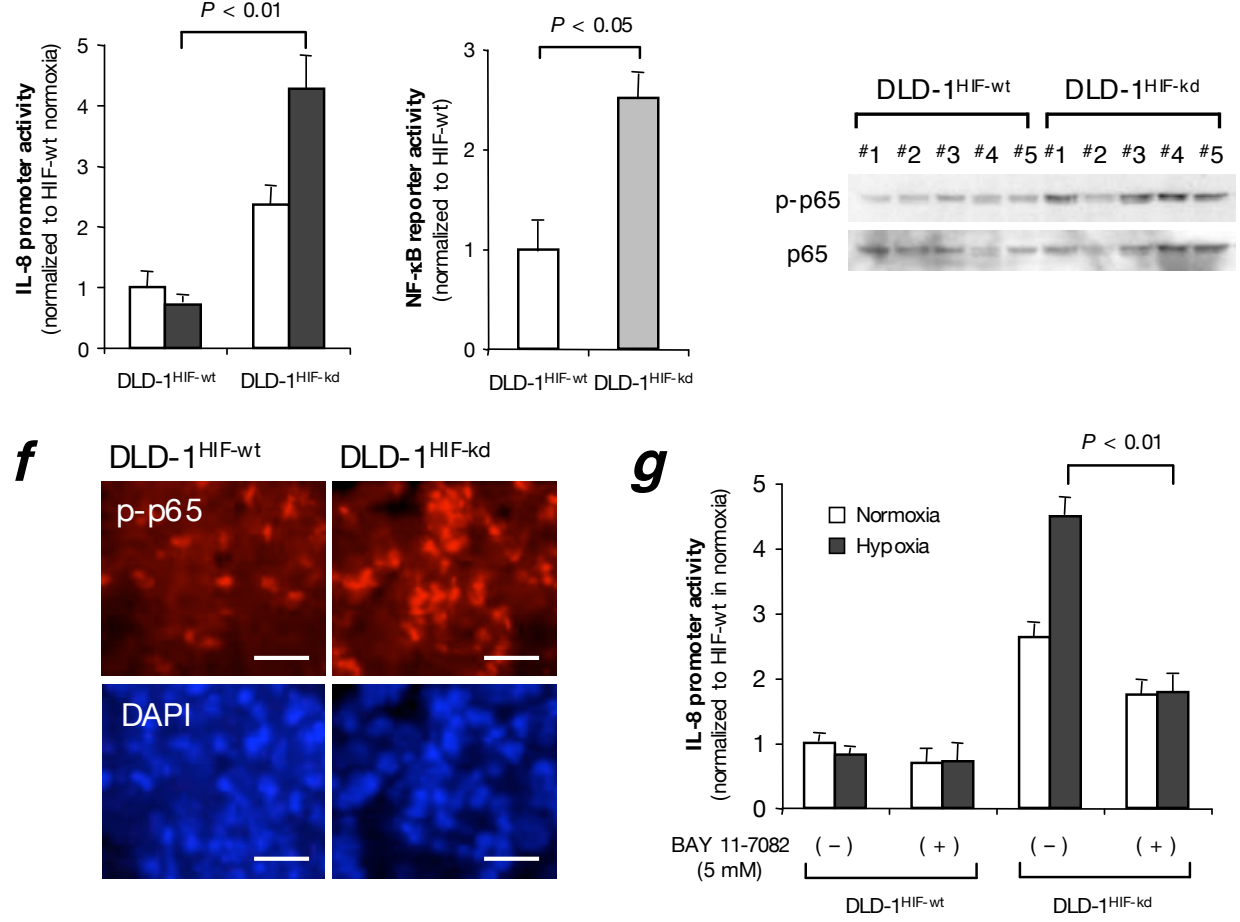
Figure 3
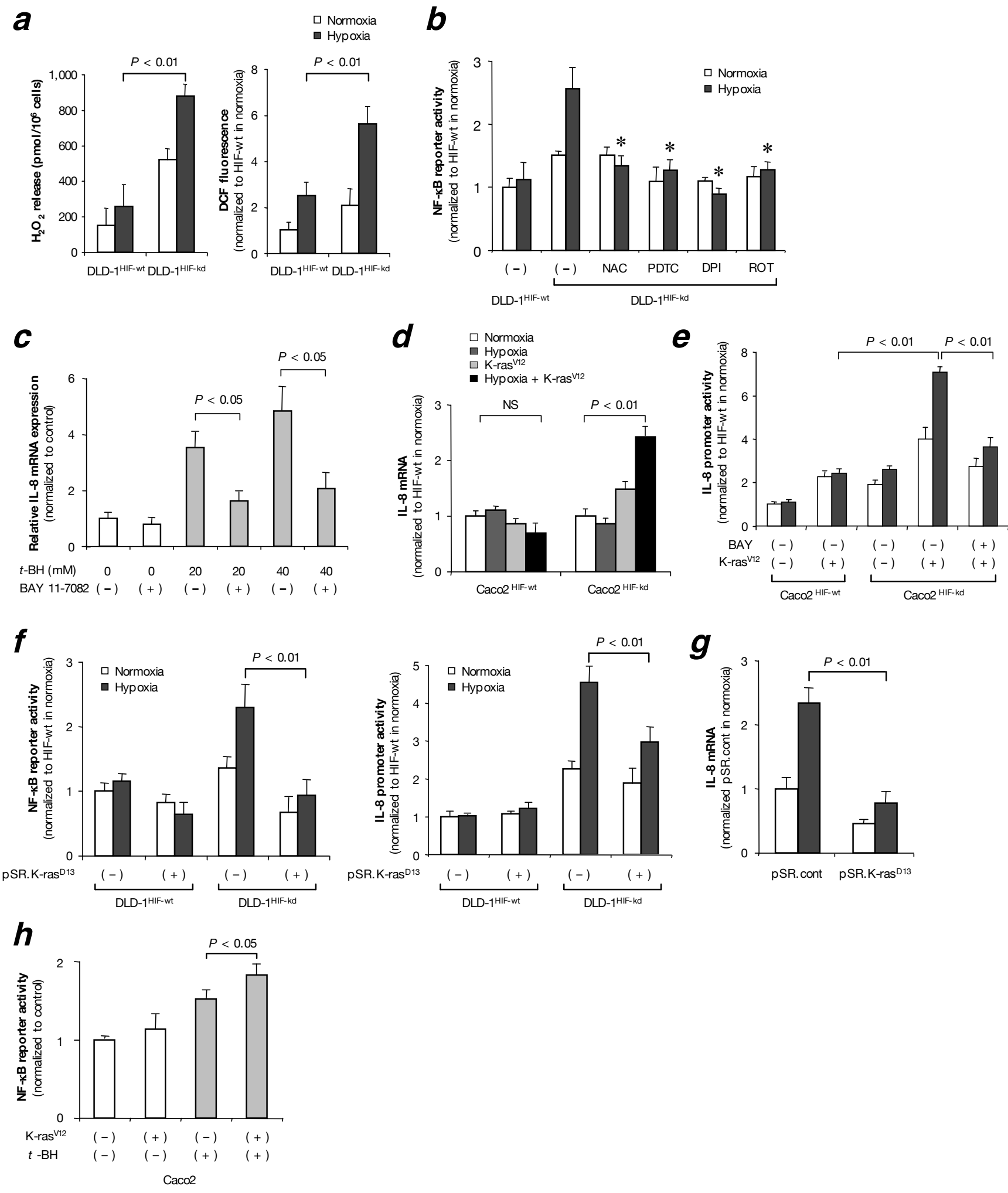


\section{Figure 4}
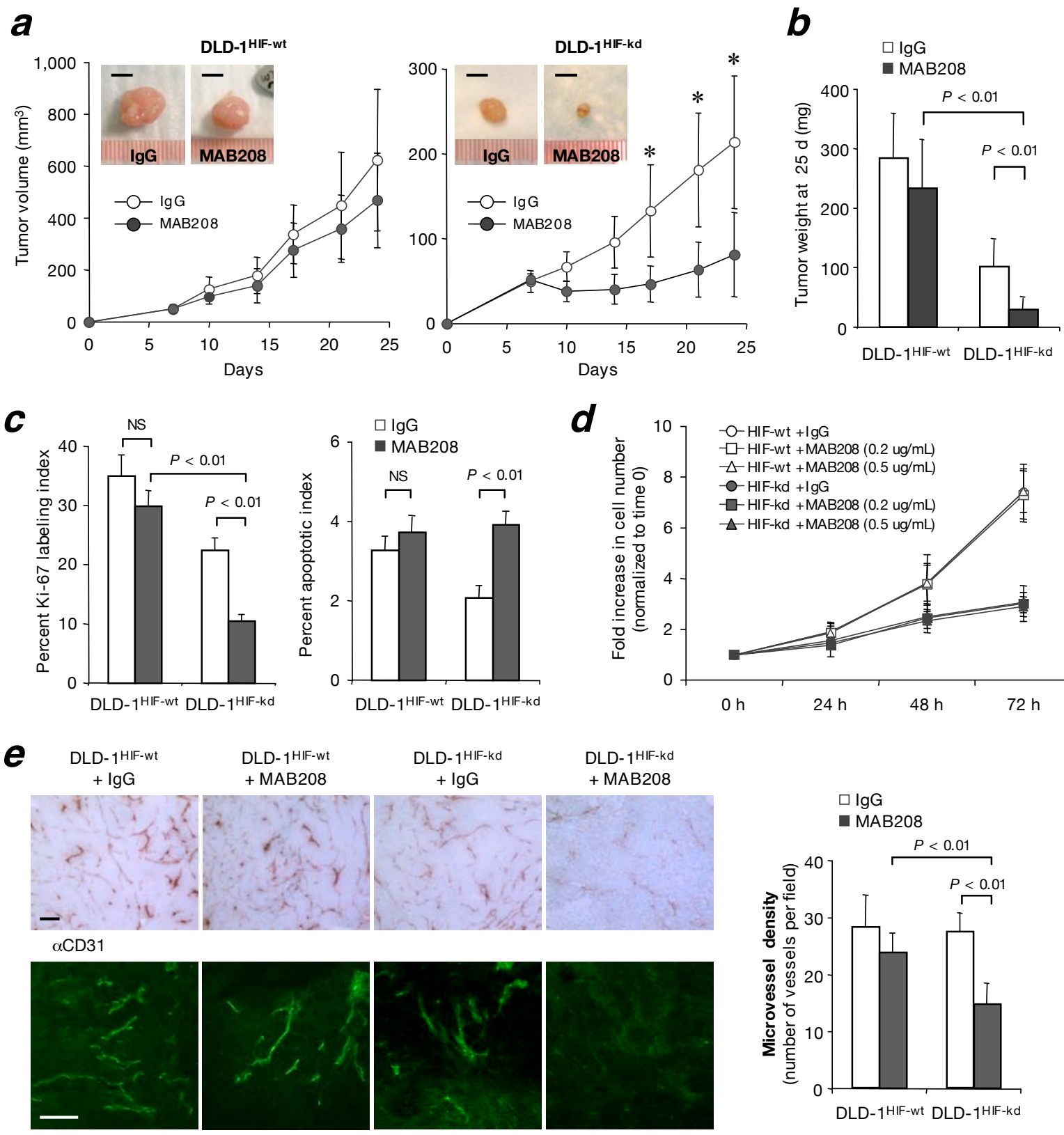

$-O-H I F-w t+$ IgG

$-\square-H I F-w t+M A B 208(0.2 \mathrm{ug} / \mathrm{mL})$ $\triangle$ HIF-wt +MAB208 $(0.5 \mathrm{ug} / \mathrm{mL})$

- HIF-kd + IgG

$-\square$ HIF-kd + MAB208 $(0.2 \mathrm{ug} / \mathrm{mL})$

$\triangle$ HIF-kd + MAB208 (0.5 ug/mL)

lectin

$f$
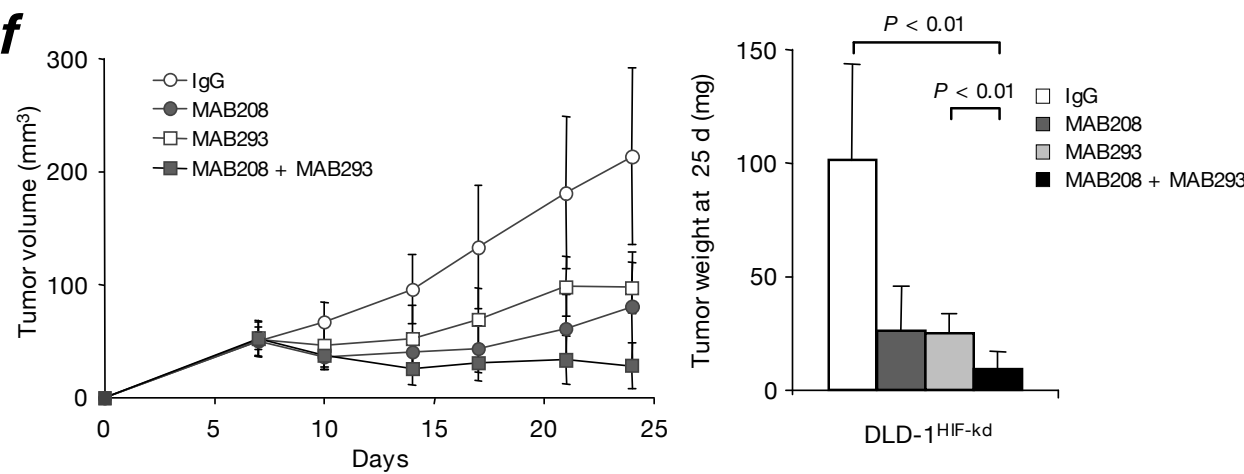

$\square \lg G$

MAB208

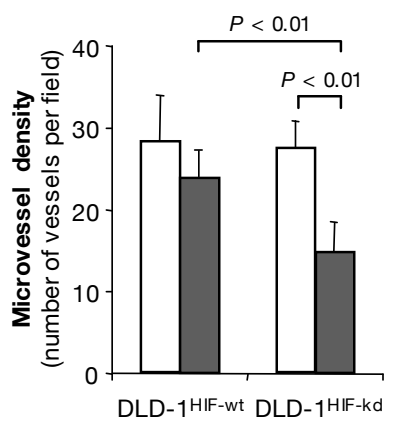




\section{Supplementary Figure 1}

a

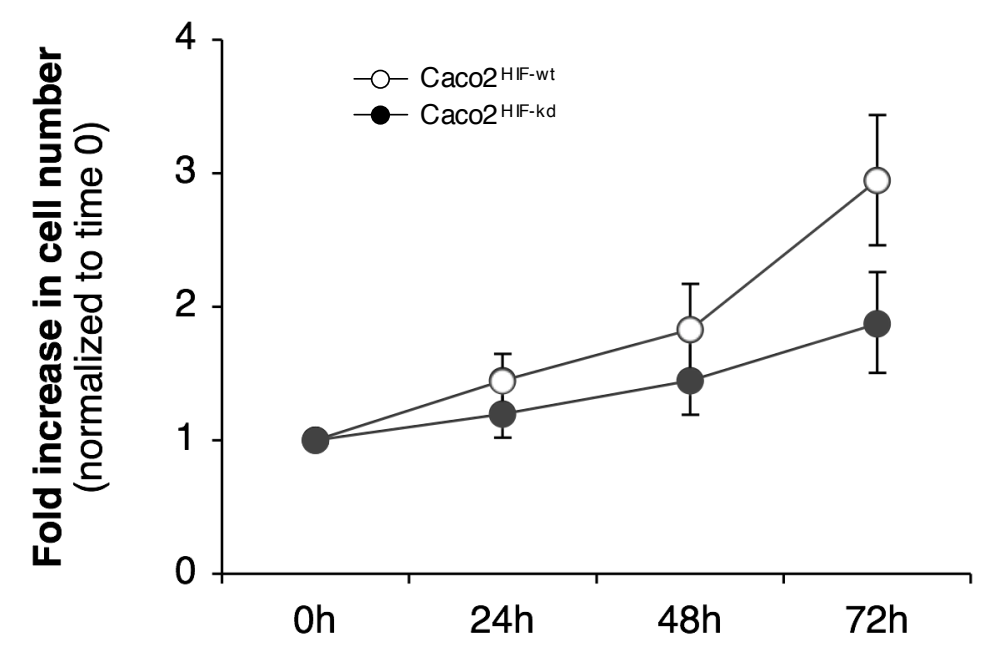

$\boldsymbol{b}$

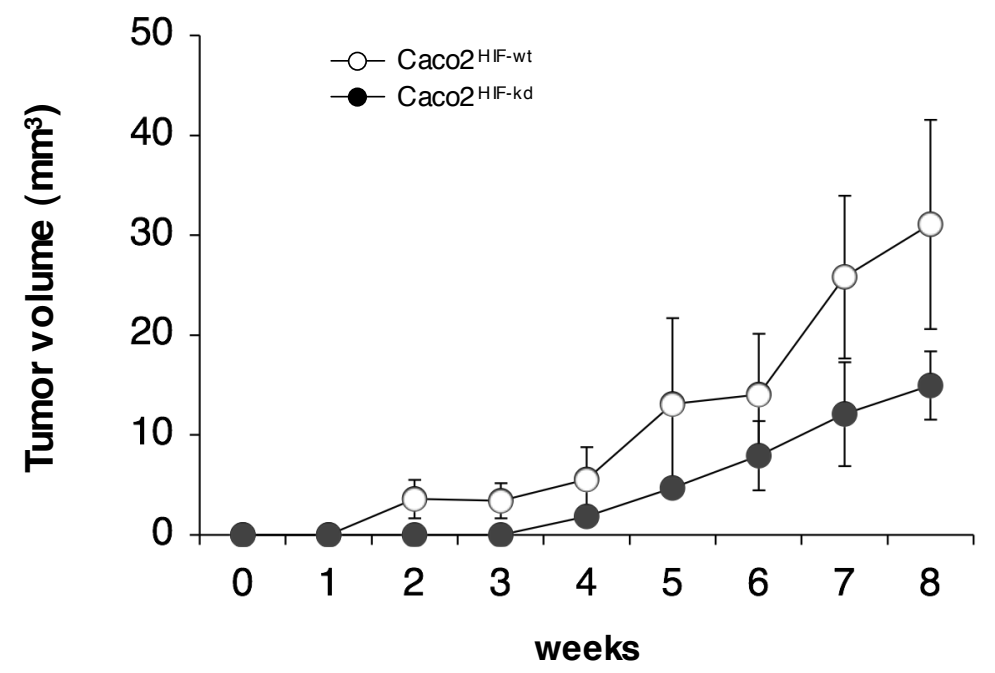

Supplementary Figure 1: Growth of $\mathrm{Caco} 2^{\mathrm{HIF}-\mathrm{wt}}$ and $\mathrm{Caco} 2^{\mathrm{HIF}-\mathrm{kd}}$ cells in vitro (a) and in vivo as xenografts in nude mice (b). The growth curves of the cells in vitro are illustrated as the fold increase compared to baseline. 


\section{Supplementary Figure 2}

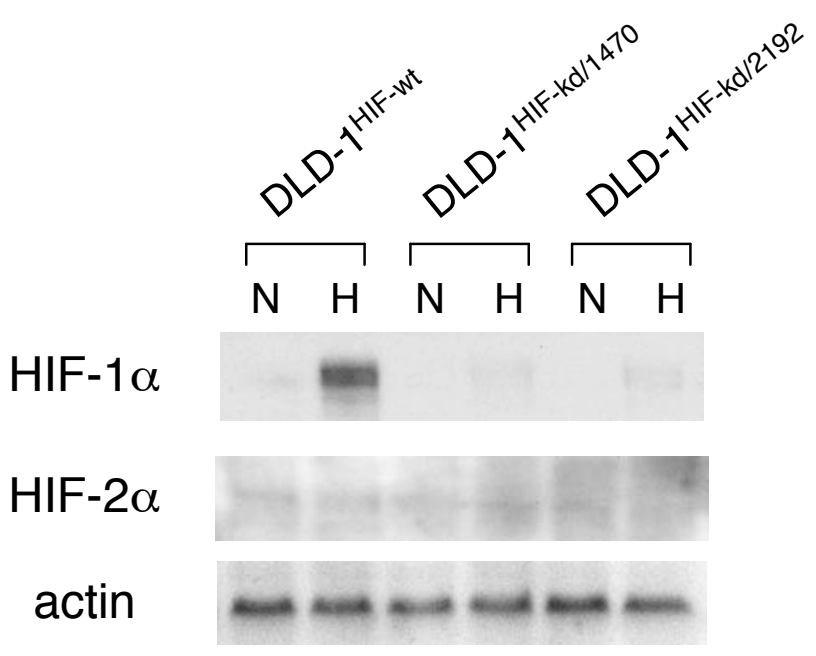

Supplementary Figure 2: Immunoblot of HIF-1 $\alpha$ and HIF-2 $\alpha$ proteins in DLD-1 ${ }^{\text {HIF-WT }}$, DLD-1 $1^{\mathrm{HIF}-\mathrm{kd} / 1470}$, and DLD-1 ${ }^{\mathrm{HIF}-\mathrm{kd} / 2192}$ cells in normoxic $(\mathrm{N})$ and hypoxic $(\mathrm{H})$ conditions. No HIF- $1 \alpha$ is detectable in the knock-down cells. HIF-2 $\alpha$ protein levels are nearly undetectable in the parental DLD-1 cells, and there is no induction of HIF- $2 \alpha$ in the HIF-1-kd cell lines in hypoxia. Similarly, DNA microarray studies indicated that mRNA levels for HIF-1 $\alpha$ fell from 1518.2 relative units in DLD- ${ }^{\text {HIF-WT }}$ cells to 124.5 relative units in DLD-1 ${ }^{\text {HIF-kd }}$ cells in hypoxic conditions. HIF- $2 \alpha$ mRNA levels, in contrast, were extremely low in DLD-1 ${ }^{\text {HIF- }}$ WT cells (54.5 relative units), and furthermore, there was no increase when HIF-1 $\alpha$ was knocked-down in DLD-1 ${ }^{\text {HIF-kd }}$ cells (43.2 relative units). 


\section{Supplementary Figure 3}

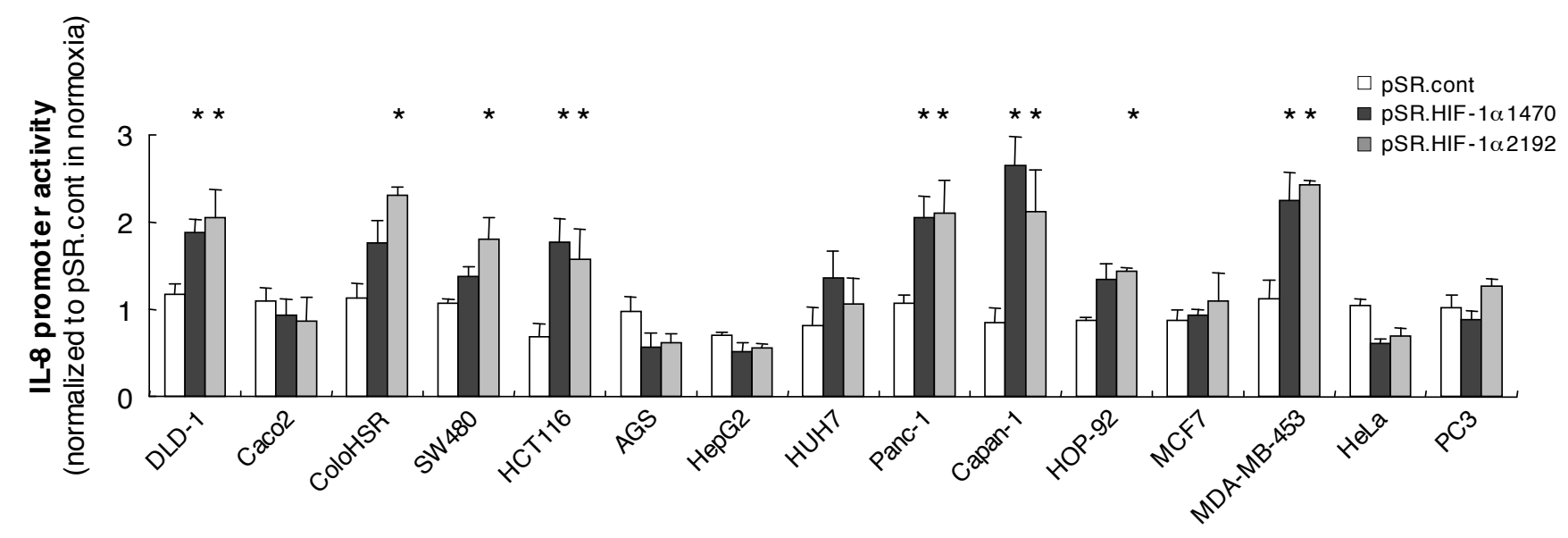

Supplementary Figure 3: The hypoxic induction of IL-8 in the absence of HIF- $1 \alpha$ is observed in many cancer cell lines. HIF-1 $\alpha$ was transiently knocked-down with two independent siRNA constructs (pSR.HIF $1 \alpha 1470$ and pSR.HIF 1 $\alpha 2192$ ), and hypoxic induction of the IL-8 promoter was measured. Induction of IL-8 was observed in DLD-1, ColoHSR, SW480, and HCT116 colon cancer cells. Among the non-coloniccell lines tested, strong induction was also observed in pancreatic cancer cells (Panc-1, CAPAN-1), breast cancer cells (MDA-MB 453), and lung cancer cells (HOP-92), but not in gastric cancer cells (AGS), hepatoma cells (HepG2, HuH7), cervical cancer cells (Hela), or prostate cancer cells (PC3). (* indicates $\mathrm{p}<0.05)$. 


\section{Supplementary Figure 4}

DLD-1 ${ }^{H I F-k d / 1470}$

Hypoxic induction of

HRE reporter activity
IL-8 promoter activity In hypoxia

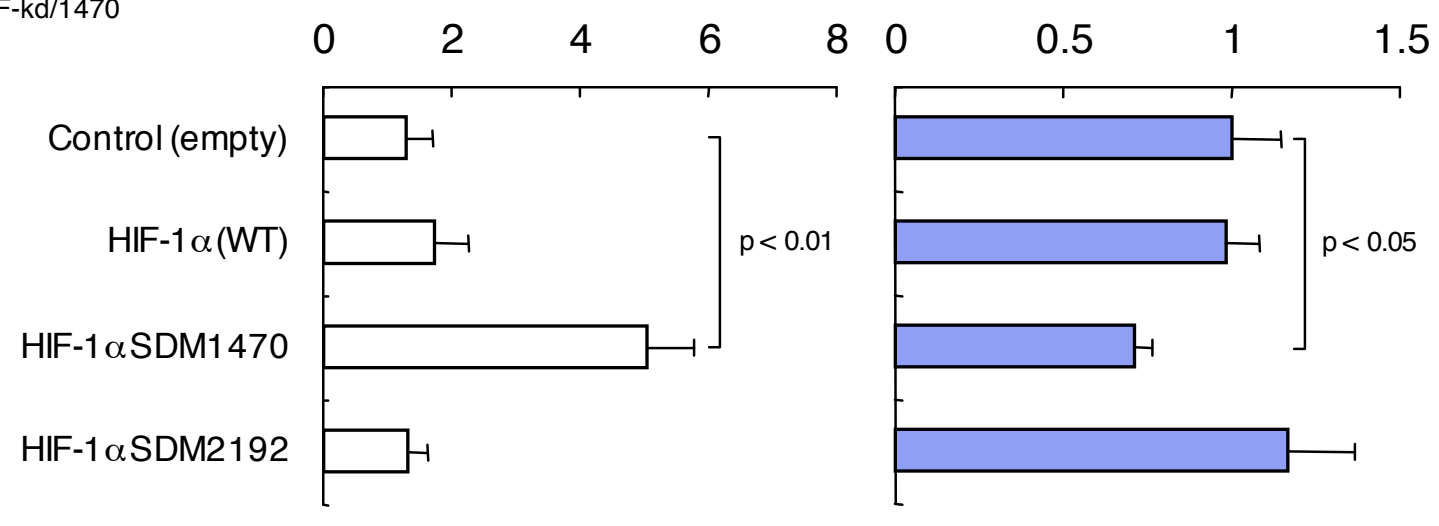

DLD-1 ${ }^{\text {HIF-kd/2192 }}$
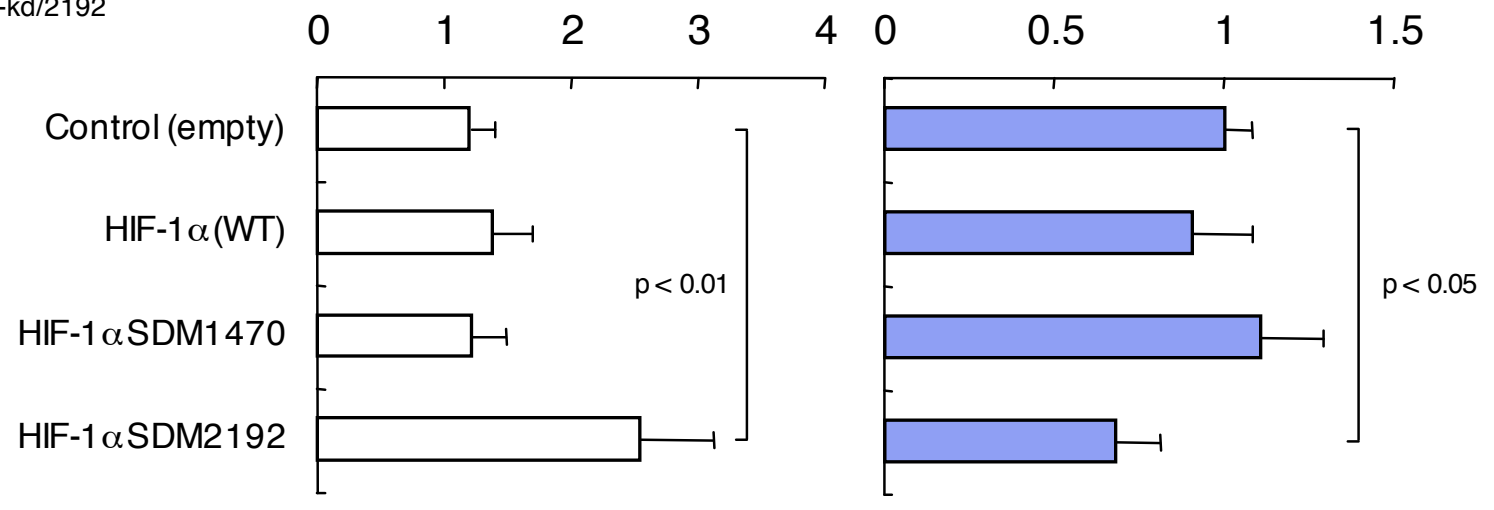

Supplementary Figure 4: Specificity of the pSR.HIF-1 $\alpha 1470$ and pSR.HIF-1 12192 constructs was demonstrated by co-expression of HIF-1 $\alpha$ expression vectors with synonymous codon mutations that are not affected by the siRNA target sequences. (Primers: SDM-HIF1470 forward 5'- AAA TTA GAA CCA AAT CCA GA A AGCCTG GAA CTT TCT TTT ACC ATG C, SDM-HIF1470 reverse 5'- GCA TGG TAA AAG AAA GTT CCA GGC TTT CTG GAT TTG GTT CTA ATT T. SDM-HIF2192 forward 5'- GAA AAA TGG AAC ATG ATG GCA GCC TTT TTC AAG CAG TAG GAA TTG G. SDM-HIF2192 reverse 5'- CCA ATT CCT ACT GCT TGA AAA AGG CTG CCA TCA TGT TCC ATT TTT C. The boxed sequence is targeted by the siRNA construct, and the underlined nucleotides indicate the point mutations introduced.) Expression of the HIF-1 $\alpha$ SDM1470 construct but not the HIF-1 $\alpha$ SDM2192 construct strongly induced HRE reporter activity in DLD- $1^{\mathrm{HIF}-\mathrm{kd} / 1470}$ cells, and the hypoxic induction of IL-8 promoter activity seen in these cells was blocked. Similar results were obtained for the HIF-1 $\alpha$ SDM2192 construct in DLD-1 ${ }^{\mathrm{HIF}-\mathrm{kd} / 2192}$ cells. 


\section{Supplementary Figure 5}

a

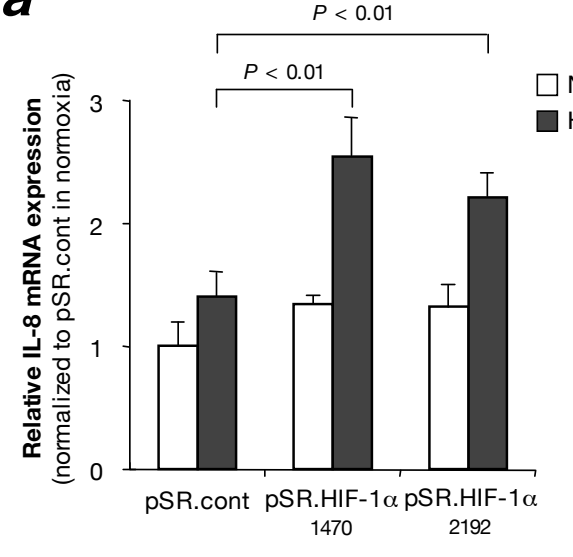

b

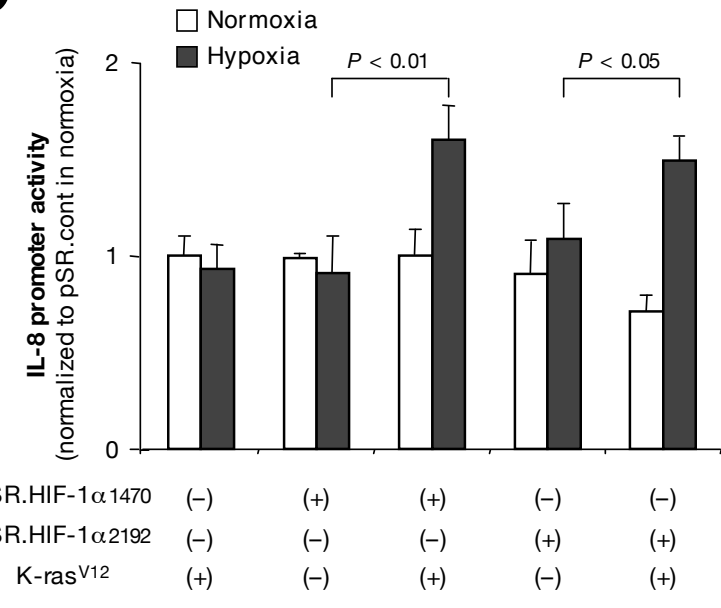

Supplementary Figure 5: Oncogenic $K$-ras plays a role in the hypoxic induction of IL-8 in noncolonic cancers. a, The pancreatic cancer cell line Panc- 1 carries a mutant $K$-ras ${ }^{D 12}$ oncogene. Knock-down of HIF- $1 \alpha$ resulted in the induction IL-8 mRNA expression in these cells (top left panel). Immunoblotting demonstrated successful knock-down of HIF-1 $\alpha$ protein (top right panel). When siRNA to $K-r^{D} s^{D 12}$ was also introduced, the hypoxic induction of IL-8 promoter activity was blunted (lower panel). $\quad \boldsymbol{b}$, In PC3 prostate cancer cells that carry a wild type $K$-ras gene, introduction of oncogenic $K-$ ras $^{V 12}$ in combination with transient knock-down of HIF-1 $\alpha$ resulted in the hypoxic induction of the IL-8 promoter. 


\section{Supplementary Table}

\begin{tabular}{lccc} 
Fragment name & Gene & $\begin{array}{c}\text { Fold induction } \\
\text { by hypoxia }\end{array}$ & $\begin{array}{c}\text { Change in hypoxic induction } \\
\text { by HIF knock-down (\%) }\end{array}$ \\
\hline 210512_s_at & VEGF-A & 4.0 & -10.6 \\
205463_s_at & PDGFA & 2.2 & 103.3 \\
204200_s_at & PDGFB & 0.7 & 35.1 \\
204421_s_at & basic FGF & 1.1 & -84.6 \\
204422_s_at & FGF2 & 0.5 & -86.6 \\
205608_s_at & angiopoietin-1 & 0.9 & -26.6 \\
202023_at & Ephrin A1 & 2.5 & -15.7 \\
205016_at & TGF- $\alpha$ & 1.2 & -44.9 \\
209747_at & TGF- $\beta 3$ & 1.6 & -19.3 \\
202859_x_at & interleukin-8 & 0.8 & 81.2 \\
210037_s_at & inducible nitric oxide synthase & 2.3 & -7.8 \\
205141_at & angiogenin & 4.0 & 14.4 \\
200785_s_at & low density lipoprotein-related protein-1 (LRP1) & 0.6 & -14.4 \\
201809_s_at & endoglin (ENG) & 6.9 & -65.7 \\
202912_at & adrenomedullin (ADM) & 3.5 & -24.4 \\
203666_at & stromal cell-derived factor-1 (SDF-1) & 2.1 & -38.8 \\
207094_at & interleukin 8 receptor, $\alpha$ (IL8RA, CXCR1) * & 0.8 & -19.2 \\
207008_at & interleukin 8 receptor, $\beta$ (IL8RB, CXCR2) * & 2.8 & -74.0 \\
\hline
\end{tabular}

*expression level in normoxia categorized as "absent" 